\title{
DYNAMICS OF POST-FIRE EFFECTS IN LARCH FORESTS OF CENTRAL SIBERIA BASED ON SATELLITE DATA
}

\author{
Nikita Yakimov ${ }^{1,3}$, and Evgenii Ponomarev $v^{1,2}$ \\ ${ }^{1}$ Federal Research Center "Krasnoyarsk Science Center of the Siberian Branch of the Russian Academy of Sciences", \\ Krasnoyarsk, 660036, Russian Federation \\ ${ }^{2}$ Sukachev Institute of Forest, Siberian Branch, Russian Academy of Sciences, Krasnoyarsk, 660036, Russian \\ Federation \\ ${ }^{3}$ Siberian Federal University, Krasnoyarsk, 660041, Russian Federation
}

\begin{abstract}
The article represents the results of Terra, Aqua / MODIS, Landsat-8/OLI satellite data analysis for fire damaged plots in larch forests of Central Siberia. The analysis of averaged surface temperature (brightness temperature) and vegetation index (NDVI) was performed for post-fire circumstances. Estimates of the state and dynamics of fire-damaged vegetation cover were obtained on the basis of interseasonal variation of the NDVI index. It was found that post-fire dynamics of vegetation cover determines the surface temperature anomalies within the fire scar plots during at least five years after wildfire impact. It was instrumentally registered that the maximum excess of brightness temperature on post-fire areas can reach up to $11^{\circ} \mathrm{C}$ comparing to that of background areas under the same conditions. Such anomalies are determined by higher level of insolation due to partial or total tree mortality, as well as by decreasing of onground cover thickness after fire impact on grass and moss-lichen covers. During the first year after a fire in larch forests of Siberia, the maximum temperature anomalies of the underlying surface was recorded in the third decade of June. In the course of 2-5 years after burning, the maximum temperature anomalies shift to the second or even third decade of July within the phenological season. The suggested approach allows to assess the degree of fire impact on vegetation, as well as to predict changes in the active layer of permafrost soils, which may be a consequence of extra thermal flow at the surface in the circumstances of disturbed larch forests of Siberia.
\end{abstract}

\section{Introduction}

Since the end of XX-begin of XXI в. there is a trend of growth in the number and area of wildfires, which determines the increase in the percentage of disturbed areas in larch forests of Central Siberia [1-5]. Boreal forests around the world are characterized by high levels of fire activity [6-7]. In Siberia, among others, the long-term cumulative effect of fire impact is expressed in the percentage of forest areas covered by fire, which reaches $20-25 \%$ over the past 20 years $[5 ; 8]$ of the total area of larch forests. Due to the impact of wildfires there are anomalies of the thermal regime of the underlying surface, which observed for a long time within disturbed forest areas [8]. Such changes are caused by a decreasing of albedo and heat-insulating properties of the litter and ground cover at the post-fire forest plots $[9 ; 10 ; 11]$. Anomalies of the thermal balance of the underlying surface can be critical for ecosystems under the conditions of the permafrost of Central Siberia [12], as an ecosystem under long-term disorders are characterized by low stability. The ecological importance of Northern forests prevails over their raw material potential [9], and the impact of wildfires can lead to significant changes in environmental conditions.

Nowadays long-term monitoring of the fire impact on the forests of Siberia cannot be carried out without the use of satellite monitoring tools $[13 ; 14]$. Thematic processing of multispectral satellite data makes it possible to identify postfire changes, as well as to evaluate their intraseasonal and interseasonal dynamics of burned areas Thus, modern approaches based on remote sensing data make it possible to control and predict the state and succession processes in forest ecosystems.

The purpose of this work - quantitative assessment of post-fire changes in larch forests, which describing the state of vegetation and ground cover during 5 years of reforestation. These data are necessary for modeling of thermal processes dynamics in the upper soil horizons and forecasting the state of seasonally thawing layer of soil under permafrost condition. Increasing areas of wildfire damage actualizes research in this direction around the world [15; 16]. For the territory of Siberia, data on temperature anomalies of the underlying surface after logging are presented [17]. The effects of long-term temperature anomalies on soils and dynamics of intra-seasonal groundwater flow of rivers were recorded [18-20]. In this paper, the following aspects are considered: absolute and relative (comparing to background plots values) anomalies of temperature and NDVI; their intra-seasonal dynamics; as well as trends of recovery of NDVI values and averaged brightness temperature of underlying surface under the conditions of 5 years 
post-fire restoration. The analysis summarizes the data obtained from satellite surveys, mainly for post-fire areas in the larch forests of the permafrost zone of Central Siberia (Evenkia).

\section{Initial data}

The materials of the satellite survey Terra/MODIS (Moderate Resolution Imaging Spectroradiometer) with a spatial resolution of 250-1000 m were used. Standard MODIS products of the L2 and L3 processing level were used (available on the USGS website, URL: https://lpdaac.usgs.gov/dataset_discovery/modis). The total surface albedo information was calibrated in the ranges $\lambda 1=0.620-0.670 \mathrm{~m}$ (channel 1 , MODIS) and $\lambda 2=0.841-0.876 \mathrm{~m}$ (channel 2, MODIS) obtained from the standard product MOD09GQ. Daily surface temperature data in the range $\lambda 3=10,780-11,280 \mathrm{~m}$ (31 channels, MODIS) were calculated from the product MOD11A1. Landsat-8/OLI satellite materials with a spatial resolution of 15-30 m (free available on the USGS website, URL: https://earthexplorer.usgs.gov) were used to compare the boundaries of wildfires.

The analysis of values averaged over 7-12 post-fire sites over a five-year period was performed. The number of plots were depended on the year and availability of informative images for phenology decades of the season. The intraseasonal variation of the studied parameters was analyzed for the growing season taking into account the phenological cycle of vegetation, the characteristic duration of the individual phases of which is about a decade.

The geographical coordinates of the site on the territory of Central Siberia: $59.8-62.5^{\circ} \mathrm{N}$ and $96.5-104^{\circ} \mathrm{E}$. The length of the research area from North to South is $330 \mathrm{~km}$, and from West to East is $400 \mathrm{~km}$. The district is located on the Central Siberian highland, the terrain is mainly mountainous, disturbed areas of the forest are represented by post-fire larch with dwarf shrub, lichen and mosses.

Anomalies of NDVI and temperature field were defined both in absolute values in comparison with background values, and in relative indicators (percent in relation to average long-term norm).

\section{Methods and data processing algorithms}

Within the boundaries of the area of interest, a selection of retrospective survey materials Terra, Aqua/MODIS, Landsat8/OLI for the period 2013-2018 was carried out. On the selected images wildfires of different years were detected, Dating was carried out using the database of fires Sukachev Institute of Forest Siberian Branch, Russian Academy of Sciences, containing materials during the period of observation 1996-2019 years. Local areas were considered, in which an average of 10 or more large fires were detected. Analysis of local wildfires made it possible to increase the information content of the image during the sub-stage examination. We selected images of this area for each of the decades of the season with maximum information. For each decade of the season, averaged values of brightness temperature of disturbed areas (31 channels) and surface albedo (1,2 channels) were obtained. Background values were recorded in the immediate vicinity of post-fire areas at a distance of 1-5 km in similar forest conditions. An example of the distribution of parameter measurement points is shown in figure 1.
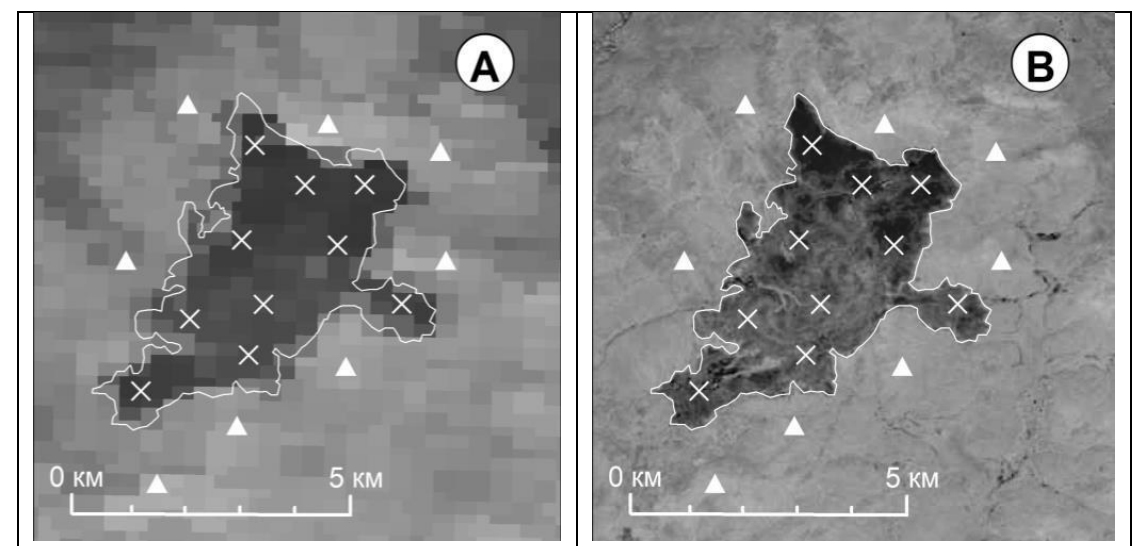

Fig. 1. Illustration of satellite images (a - Terra/MODIS, B-Landsat-8/OLI) of wildfire. Date of images - 23.06.2018. Conventional marks indicate the points of selection of spectral data on the brightness temperature and albedo of the underlying surface inside the fire range $(\mathrm{X})$ and background values in the immediate vicinity ( $\boldsymbol{\Delta})$. Central Siberia, Evenkia, 2018

The obtained temperature values of the disturbed and background areas were applied to identify sub-cascade temperature anomalies. Albedo values were applied to calculate NDVI values averaged for each decade. On the basis of the obtained data, the dynamics of changes in the temperature anomaly and NDVI index in 1, 2, 4, 5 years after fires 
were constructed. There are no 2015 data defining the situation in the 3rd year after the fire, due to the low number of fires in the research area (2 fires) and in the territory of Evenkia as a whole.

\section{Results and Discussion}

In the first year after the wildfires, the temperature anomaly averaged $5^{\circ} \mathrm{C}$ for the summer and $4.6^{\circ} \mathrm{C}$ for the entire period of research (taking into account the third decade of May and the first decade of September). The maximum temperature recorded in the $3 \mathrm{rd}$ decade of June was $11^{\circ} \mathrm{C}$ (Fig.1/A). On average, the temperature in the 3rd decade of June was kept at $7.5^{\circ} \mathrm{C}$. Such data are equivalent to the data obtained in other works $[18,19]$. It has been suggested that the high level of insolation is caused by the oppression of the grass and moss-lichen covers and the low amount of tree mortality. In subsequent post-fire years, the maximum temperature values are shifted to mid-summer, 2-3 decade of July (Fig.1/B-D). This is confirmed by the data of field research [10]. In the second year after wildfires there is a decrease in the average temperature anomaly up to $40-47 \%$ depending on the decades. The average decline over the entire period is $27 \%$. The maximum temperature anomaly was recorded in the 2 nd decade of July and amounted to $7.64^{\circ} \mathrm{C}$, which is $31 \%$ lower than the maximum temperature anomaly of the previous season. However, in the case of comparing the values of the second decade of July, this value decreased by only $15 \%$. The values of the temperature anomaly with this decrease are $3.6^{\circ} \mathrm{C}$ for the summer period and $3.3^{\circ} \mathrm{C}$ for the whole period. In the fourth year after the fires, the temperature anomaly averaged $2.9^{\circ} \mathrm{C}$ for the summer and $2.7^{\circ} \mathrm{C}$ for the entire period. Thus, there was a decrease in the average temperature anomaly by $41 \%$ relative to the first year and by $19 \%$ relative to the second year. The maximum anomaly recorded in the 2 nd decade of July $-5.34^{\circ} \mathrm{C}$. In the fifth year of the recovery succession, the temperature anomaly decreased to $2.4^{\circ} \mathrm{C}$ over the summer and $2.3^{\circ} \mathrm{C}$ over the entire research period. The value of the temperature anomaly decreased by $50 \%$ relative to the first year, by $32 \%$ relative to the second year and by $15 \%$ relative to the fourth year. We observe a decrease in the temperature anomaly for five years, but during this time the difference in the temperatures of the disturbed and background values remains on average above $2 \pm 0.51^{\circ} \mathrm{C}$. The Dynamics of the absolute temperature values is demonstrated in Fig. 2.

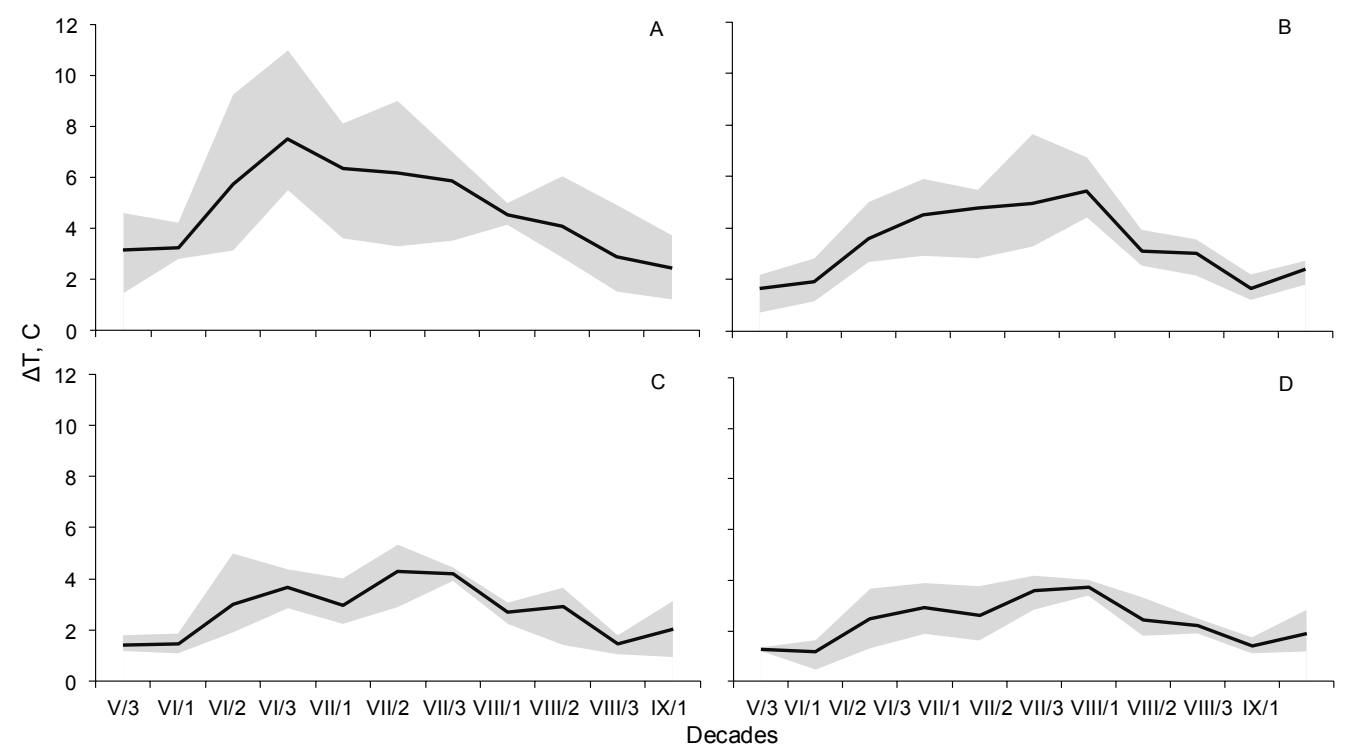

Fig. 2. Seasonal dynamics of absolute values of radio brightness temperature in the territory of Central Siberia (Evenkia) in relation to the background in 1(a), 2(B), 4(C), 5 (D) year after fires. On the $\mathrm{x}$ axis, the months/decades of the season are allocated: V-may, VI-June..., IX-September; 1, 2, 3-the name of the decades of months.

Based on the obtained values for the five years of recovery, it can be seen that the difference between the values of the temperature anomaly for the summer season and for the full period, including the values of the 3rd decade of May and the 1st decade of September, decreases and practically levels. This is due to the restoration of vegetation, which in turn smoothes the amplitude of the spread of minimum and maximum values. It is assumed that changes in the temperature anomaly by the sixth year of the recovery succession, differences in the temperatures of the disturbed areas, at the boundaries of the spring-summer and summer-autumn periods, will be at the level of error.

The whole season was divided into 3 time periods - early season (may-June), mid-season (July), late season (August-September). Thus, the obtained values of the relative brightness temperature anomaly in all post-fire successions showed a normal distribution of values with a maximum of temperature values in the middle of the season 
and low temperatures at the beginning and end of the season. The brightness temperature anomaly relative to the background values is shown in Table 1 .

Tab 1. Relative anomaly of brightness temperature and NDVI

\begin{tabular}{|l|c|c|c|c|c|c|c|c|}
\hline & \multicolumn{7}{|c|}{ Average anomaly of brightness temperature and NDVI, \% } \\
\cline { 2 - 9 } & \multicolumn{2}{|c|}{1 year } & \multicolumn{2}{c|}{2 year } & \multicolumn{2}{c|}{4 year } & \multicolumn{2}{c|}{5 year } \\
\cline { 2 - 9 } & $\mathrm{T}_{\text {rel }}$ & NDVI & $\mathrm{T}_{\text {rel }}$ & NDVI & $T_{\text {rel }}$ & NDVI & $T_{\text {rel }}$ & NDVI \\
\hline May-June & $24,3 \pm 8,9$ & $62,4 \pm 1,8$ & $13,5 \pm 4,5$ & $43,8 \pm 4,0$ & $11,2 \pm 3,3$ & $35,3 \pm 3,3$ & $9,8 \pm 3,0$ & $32,7 \pm 5,4$ \\
\hline Jule & $29,1 \pm 2,5$ & $56,7 \pm 10,0$ & $24,5 \pm 5,7$ & $42,9 \pm 3,2$ & $18,0 \pm 7,1$ & $29,6 \pm 3,9$ & $15,0 \pm 7,0$ & $28,1 \pm 0,8$ \\
\hline $\begin{array}{l}\text { August- } \\
\text { September }\end{array}$ & $22,5 \pm 5,4$ & $51,0 \pm 4,8$ & $13,8 \pm 4,5$ & $39,8 \pm 1,3$ & $12,6 \pm 3,5$ & $34,4 \pm 5,1$ & $11,0 \pm 3,5$ & $34,5 \pm 3,4$ \\
\hline
\end{tabular}

It is expected that the rate of decline of the temperature anomaly will continue, but less intensively, as the relative decline was $27 \%$ in the second year and fell to $15 \%$ by the fifth year, relative to previous years. Insolation of the underlying surface leads to a significant rise in surface temperature in the first year after the fire, but in subsequent years this value decreases. However, according to preliminary calculations of the temperature anomaly, at several fire stations in 2012 , it reached $5^{\circ} \mathrm{C}$, which is similar to the average for the first year.

NDVI values have also been declining annually for five years. The difference between the values for the entire research period and the values only for the summer period does not exceed $1 \%$. Therefore, it is not necessary to divide the obtained values by the system (by the average for the summer period and the average for the whole period), as in the case of a temperature anomaly. The values of the relative anomaly of the vegetation index are presented in Table 1 . The dynamics of the vegetation index NDVI is shown in Fig. 3.

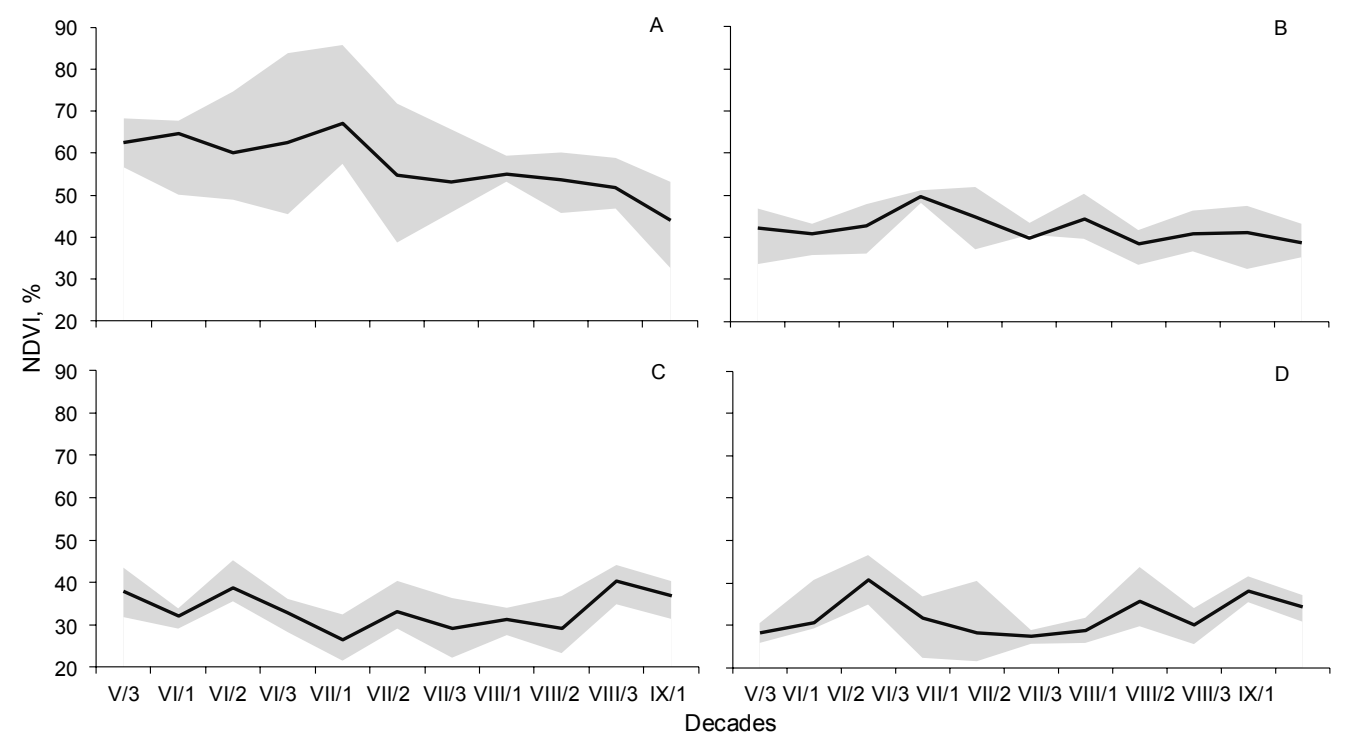

Fig. 3. Dynamics of vegetation index (NDVI) changes in 1(a), 2(B), 4(C), 5 (D) year after wildfires in Central Siberia (Evenkia). The dynamics of averaged values with limits in minimum and maximum values for each decade is illustrated. On the $\mathrm{x}$ axis, the months/decades of the season are allocated: V-may, VI-June..., IX-September; 1, 2, 3-the name of the decades of months.

In the first year after the fire, NDVI background values are higher than disturbed areas by an average of $56 \%$, in some cases this value reaches $86 \%$ (in July), due to the high degree of oppression of vegetation cover in disturbed areas. In the second year, this anomaly decreased to $42 \%$, and the maximum values reached $53 \%$. Differences in indicators are smoothed out, consequently, there is a process of restoration of photosynthetic activity of vegetation. In the fourth year, this value of the vegetation anomaly decreased to $33 \%$, and the maximum values were at the level of $44 \%$. By the fifth year, there is a minimal decrease in the indicator of the NDVI anomaly, relative to previous years. The difference between the fourth and fifth years is $2 \%$. The total excess of background values over the values of disturbed areas in the fifth year was $31 \%$, and the maximum values reached $40 \%$. 
During the vegetation season, the average background NDVI was at 0.6. Consequently, the decrease in the NDVI anomaly is caused by an increase in the NDVI indicators of the disturbed areas. The highest amplitude of NDVI values is observed in the first year of reforestation. Starting from the second year, the amplitude of the values is significantly reduced.

\section{Conclusions}

Extra insolation, as a consequence of reducing the albedo within the post-fire areas, induces extra heating of the underlying surface. It was instrumentally registered that the maximum excess of brightness temperature on post-fire areas can reach up to $11^{\circ} \mathrm{C}$ comparing to that of background areas under the same conditions. Such anomalies are determined by higher level of insolation due to partial or total tree mortality, as well as by decreasing of on-ground cover thickness after fire impact on grass and moss-lichen covers. During the vegetation season, averaged abnormal surface temperature is within the range of $4.74 \pm 1.0^{\circ} \mathrm{C}$. The temperature maximum is decreasing by $29 \%, 42 \%$ and $51 \%$ during the second, fourth and the fifth year after fire respectively. However, the maximum temperature anomalies even after 5 years of vegetation recovery are staying at value of $4^{\circ} \mathrm{C}$.

During the first year after a fire in larch forests of Siberia, the maximum temperature anomalies of the underlying surface was recorded in the third decade of June. In the course of 2-5 years after burning, the maximum temperature anomalies shift to the second or even third decade of July within the phenological season.

Analysis of NDVI indicators showed a trend of decreasing vegetation anomaly from the beginning to the end of the season in the first and second year of reforestation. During the fourth and fifth year of reforestation, the lowest anomalies were observed in the middle of the season (July). This means that the restoration of vegetation, starting from the fourth year, has reached a level at which the difference between background indicators and indicators of disturbed areas is reduced by increasing photosynthetic activity in disturbed areas. While during the first and second year of reforestation, this was due to a decrease in the photosynthetic activity of the background vegetation.

Based on the observed temperature anomalies and the NDVI anomalies could be concluded, that five years of postfire succession is not enough to stabilize the disturbed plots relative to the background condition, both in the case of temperature changes and in the case of photosynthetic activity of vegetation. The suggested approach allows to assess the degree of fire impact on vegetation, as well as to predict changes in the active layer of permafrost soils, which may be a consequence of extra thermal flow at the surface in the circumstances of disturbed larch forests of Siberia.

Acknowledgments: This research was funded by the Russian Foundation for Basic Research (RFBR) and Government of the Krasnoyarsk krai, and Krasnoyarsk krai Foundation for Research and Development Support, grant number 18-41-242003 "Modeling and satellite monitoring of effects from thermal anomalies of the underlying surface in the seasonally thawed soil layer of the permafrost zone of Siberia".

\section{References}

1. Ponomarev E.I., Kharuk V.I., Ranson J. K. Forests, 7, 1-9 (2016)

2. Shvidenko, A.Z. Schepaschenko, D.G., Contemp. Probl. Ecol., 7, 50-61 (2013)

3. Valendik E.N., Kisilyakhov E.K., Ryzhkova V.A., Ponomarev E.I., and Danilova I.V. Geography and Natural Resources, 35, 41-47 (2014)

4. $\quad$ Ponomarev E.I., Kharuk V.I Contemporary Problems of Ecology, 9, 29-36 (2016)

5. Kharuk V.I., Ponomarev E.I. Russian Journal of Ecology, 48, 507-512 (2017)

6. de Groot, W.J., Cantin, A.S., Flannigan, M.D., et al., For. Ecol. Manage., 294, 23-34 (2013)

7. Flannigan, M., Cantin, A.S., and de Groot, W.J., For. Ecol. Manage., 294, 54-61 (2013)

8. Ponomarev E.I., Ponomareva T.V. Contemporary Problems of Ecology, 11, 420-427, (2018)

9. Tsvetkov P.A. Conifers of the boreal zone, 5, 10-14 (2013)

10. Bezkorovaynaya, I.N.; Borisova, I.V.; Klimchenko, A.V.; Shabalina, O.M.; Zakharchenko, L.P.; Il'in, A.A.; Beskrovny, A.K. Vestn. KrasGAU, 9, 181-189 (2017)

11. Brown, D.R.N.; Jorgenson, M.T.; Kielland, K.; Verbyla, D.L.; Prakash, A.; Koch, J.C. Remote Sens, 8, 654

(2016)

12. Knorre, A.A.; Kirdyanov, A.V.; Prokushkin, A.S.; Krusic, P.J.; Buntgen, U. Sci. Total Environ, 652, 314-319

(2019)

13. Bartalev, S.A., Stytsenko, F.V., Egorov, V.A., and Lupyan, E.A., Lesovedenie, 2, 83-94 (2015)

14. Bondur, V.G., Gordo, K.A., and Kladov, V.L., Izvestiya, Atmos. Ocean. Phys., 53, 859-874 (2017)

15. Veraverbeke S., Verstraeten W.W., Lhermitte S., Van De Kerchove R., Goossens R. International Journal of Wildland Fire, 21, 243-256 (2012)

16. Cuevas-Gonzalez M., Gerard F., Balzter H., Rianos D. Global Change Biology, 15, $561-577$ (2009)

17. Krasnoshchekov K.V., Dergunov A.V., Ponomarev E.I. Sovremennye problemy distantsionnogo zondirovaniya Zemli iz kosmosa, 16, 87-97 (2019) 
18. Yakimov N.D., Ponomarev O.I., Ponomarev E.I. Actual problems of fire safety and emergency protection, 421-429 (2019)

19. Ponomarev E.I., Ponomareva T.V. Sovremennye Problemy Distantsionnogo Zondirovaniya Zemli iz Kosmosa, 15, 85-95 (2018)

20. Ponomarev E., Ponomareva T., Masyagina O., Shvetsov E., Ponomarev O., Krasnoshchekov K., Dergunov A. Proceedings, 18, 6-7 (2019)

21. Tsvetkov P.A. Conifers of the boreal zone, 23, 186-195 (2006) 